\title{
Before-and-After Study of Interruptions in a Pharmacy Department
}

\author{
Aurélie Guérin, Élaine Caron, Denis Lebel, and Jean-François Bussières
}

\begin{abstract}
Background: Few data exist on interruptions in the drug-use process in hospital pharmacies and their effects on patient care.

Objective: The primary objective was to compare the hourly number of stimuli received and emitted (i.e., generated) by pharmacists and pharmacy technicians before and after implementation of measures intended to reduce interruptions. The secondary objective was to evaluate the impact of the corrective measures on 4 specific stimuli.
\end{abstract}

Methods: This before-and-after cross-sectional observational study was conducted in the main dispensing area of the pharmacy department of a Canadian university hospital centre. Stimuli received and emitted by pharmacists and pharmacy technicians were counted before (2010) and after (2012) implementation of corrective measures designed to limit interruptions. The effect of corrective measures on targeted stimuli was measured with a $t$ test.

Results: Data were collected during a total of 93 randomly scheduled 30-min observation periods: 62 periods in $2010(n=2663$ stimuli $)$ and 31 periods in 2012 ( $n=1217$ stimuli). The average hourly stimulus rate ( \pm standard deviation) was unchanged after implementation of corrective measures: $85.9 \pm 22.2$ in 2010 and $78.5 \pm 20.1$ in $2012(p=0.06)$. However, a significant decline was observed for many individual stimuli, including the number of face-to-face nonprofessional conversations among pharmacists $(4.4 \pm 4.2$ in 2010 versus $1.2 \pm 1.8$ in 2012, $p=0.003)$.

Conclusion: Despite the implementation of corrective measures, there was no statistically significant change in the hourly stimulus rates from 2010 to 2012 . Other studies are needed to better characterize the nature and repercussions of stimuli, distractions, and interruptions.

Key words: hospital pharmacy practice, drug-use process, interruptions, distractions, stimuli

Can J Hosp Pharm 2013;66(1):8-12

\section{RÉSUMÉ}

Contexte : Il existe peu de données sur les interruptions dans le processus de distribution des médicaments au sein des pharmacies d'hôpitaux et de leurs effets sur les soins aux patients.

Objectif : Le principal objectif était de comparer le nombre de stimuli reçus et émis (c.-à-d. engendrés) à l'heure par les pharmaciens et les assistants techniques en pharmacie avant et après la mise en ouvre de mesures correctives visant à limiter les interruptions. L'objectif secondaire était d'évaluer l'incidence des mesures correctives sur quatre stimuli particuliers.

Méthodes : Il s'agit d'une étude d'observation transversale pré- et post-intervention menée dans la principale aire de distribution du service de pharmacie d'un centre hospitalier universitaire canadien. Les stimuli reçus et émis par les pharmaciens et les assistants techniques en pharmacie ont été comptés avant (2010) et après (2012) la mise en œuvre de mesures correctives visant à limiter les interruptions. L'effet de ces mesures sur les stimuli ciblés a été mesuré au moyen d'un test t.

Résultats : Les données ont été collectées au cours de 93 périodes d'observation aléatoires de 30 minutes : 62 périodes en $2010(n=2663$ stimuli) et 31 périodes en 2012 ( $n=1217$ stimuli). Le taux moyen de stimuli par heure ( \pm l'écart type) est demeuré inchangé après la mise en ouvre des mesures correctives : 85,9 $\pm 22,2$ en 2010 et 78,5 $\pm 20,1$ en $2012(p=0,06)$. Cependant, plusieurs stimuli ont individuellement baissé de façon significative, dont le nombre de conversations non professionnelles en personne parmi les pharmaciens (4,4 \pm 4,2 en 2010 contre $1,2 \pm 1,8$ en 2012, $p=0,003$ ).

Conclusion : Malgré la mise en œuvre de mesures correctives, aucun changement statistiquement significatif n'a été observé dans les taux de stimuli par heure entre l'année 2010 et l'année 2012. D'autres études sont nécessaires afin de mieux caractériser la nature et les répercussions des stimuli, des distractions et des interruptions.

Mots clés : pratique de la pharmacie hospitalière, processus de distribution des médicaments, interruptions, distractions, stimuli

[Traduction par l'éditeur] 


\section{INTRODUCTION}

$\mathrm{F}$ lynn and others ${ }^{1}$ defined an interruption in the pharmacy context as "the cessation of productive activity before the current prescription-filling task was completed for any externally imposed, observable, or audible reason." However, no consensus exists in the literature in terms of defining interruptions in health care settings in general and pharmacy practice in particular.

Stimuli, distractions, and interruptions can increase health care providers' stress, discomfort, and dissatisfaction, and they can have an overall negative effect on ergonomics. ${ }^{2}$ In hospital practice, health care providers need sustained and distributed levels of attention to complete tasks efficiently. ${ }^{3}$ Sinclair and others ${ }^{4}$ demonstrated that a pharmacy validation task that is being interrupted requires $27 \%$ more time than its uninterrupted counterpart. Moreover, some authors have established a link between interruptions and medication errors at various steps in the drug-use process. ${ }^{1,2,5}$

Although the effect of interruptions on the attention of health care staff has been well described in the literature, only a few useful suggestions about reducing interruptions have been published. In pharmacy practice, Beso and others ${ }^{5}$ proposed that one member of the pharmacy department, positioned at an assigned station, be dedicated to responding to various questions posed by nonpharmacy personnel, so that other members of the pharmacy team are not interrupted while dispensing medications. In a newsletter on the subject of distractions, the United States Pharmacopeial Convention ${ }^{6}$ proposed 5 suggestions to reduce interruptions: conduct an analysis of failure modes, their effects, and their criticality to identify sources of distraction; remove telephones from areas where staff are performing duties related to prescribing, distributing, and administering medications; prepare a checklist of the steps related to complex tasks, in optimal order; offer continuing training on the importance of complex tasks and how to reduce interruptions; and determine interruptions that are unacceptable within the context of the operations and post signs indicating targeted zones where such interruptions should be avoided.

Given the paucity of data on interruptions in hospital pharmacies, we evaluated and compared the number of interruptions before (in 20107) and after (in 2012) implementation of corrective measures.

\section{METHODS}

\section{Design and Objectives}

The main objective of this before-and-after cross-sectional observational study was to evaluate the effect of corrective measures implemented in 2011 on the hourly number of stimuli received and emitted (generated) by pharmacists and pharmacy technicians. The secondary objective was to evaluate the effect of corrective measures on 4 stimuli that were directly targeted by the corrective measures.

\section{Setting}

The study was conducted in the main dispensing area of the pharmacy department in the Centre hospitalier universitaire Sainte-Justine, a 500-bed mother-child teaching institution in Montréal, Quebec. The area consisted of 3 data entry stations, with one pharmacist and one pharmacy technician assigned to each, along with a reception wicket. The dispensing area was centrally located within the pharmacy department.

\section{Pilot Phase}

A 2-h pilot session was conducted on August 12, 2010, to identify all types of stimuli received and emitted by pharmacists and pharmacy technicians. Of interest were stimuli that were either seen or heard by the study subjects. The research assistant who identified stimuli during this phase classified each one as systematically causing or not systematically causing an interruption. A stimulus was classified as systematically causing an interruption if it was performed by the subject (e.g., conversation, Web browsing) or if it could not be ignored by the subject (e.g., a fire alarm). An interruption was defined as any break in the primary task to the benefit of a secondary task that might or might not be relevant to the primary task.

A total of 25 stimuli were identified, 15 of which were classified as systematically causing an interruption (marked by an asterisk in the lists that follow). In total, 20 types of stimuli were received by subjects: general calls through the main hospital speaker system, other people's conversations in the target area, noise from the printer/fax machines, noise from the pneumatic tube system, noise from hand-dryers, other people's phones ringing, other people answering the phone, comings and goings, fire alarms, ${ }^{*}$ Web browsing (including social media sites such as Facebook), ${ }^{*}$ alerts from packing machines, ${ }^{*}$ technical problems, ${ }^{*}$ colleagues' questions, ${ }^{*}$ interactions with people at the reception wicket, ${ }^{*}$ information searches for prescription entry and validation, ${ }^{*}$ resolution of prescription entry issues, ${ }^{*}$ task changes, ${ }^{*}$ subject's phone ringing, ${ }^{*}$ provision of answers to colleagues, ${ }^{*}$ and miscellaneous stimuli, ${ }^{*}$ including head movements. The remaining 5 types of stimuli were emitted by the subjects: transferring phone calls, talking to oneself, face-to-face nonprofessional conversations, ${ }^{*}$ face-to-face professional conversations, ${ }^{*}$ and miscellaneous stimuli, ${ }^{*}$ including interactions with people that were not classified as face-to-face nonprofessional and professional conversations.

\section{Observational Phases}

The before-intervention phase of the study was carried out between August 17 and September 2, 2010. The afterintervention phase of the study was conducted between June 19 and June 29, 2012. 


\section{Corrective Measures}

Four specific corrective measures to reduce stimuli and interruptions were implemented in 2011, between the 2 observational phases. These corrective measures were selected by the department's management team according to the availability of suitable human and material resources. First, the dispensing area was partly reorganized, with a more enclosed layout, to reduce noise caused by people moving from one place to another within the area. Second, the 2 printer/fax machines were replaced with a digital fax server, which had a doublescreen installation for each pharmacist - pharmacy technician pair, for use during order entry and validation. Third, reminders were given about limiting nonprofessional discussions. Finally, browsing social media sites was prohibited, to limit unnecessary stimuli from ongoing Web-based discussions. The reminders to staff about limiting nonprofessional discussions may also have affected several other sources of interruptions, such as other people's conversations in the area, comings and goings, Web browsing (sites other than social media), and talking to oneself. Moreover, some sources of interruptions cannot be easily controlled by pharmacy staff, such as general calls through the main hospital speaker system, fire alarms, alerts from packing machines, and other technical problems.

\section{Data Collection}

Observations were conducted during daytime hours, between 0800 and 1600. All observations, including those during the pilot phase, were conducted by a research assistant with a good understanding of the pharmacists' and technicians' duties. Pharmacy staff had been notified in advance, by e-mail, that a study about noise and interruptions would be conducted, but the dates and times of the observation periods were not revealed in advance.

A data collection sheet was developed according to stimuli identified in the pilot phase and was pretested before the observational phases. The observer sat in the middle of the dispensing area (on average $4 \mathrm{~m}$ from most subjects observed) at a fixed, predetermined location that had no effect on pharmacy operations. The observer was not allowed to interact in any manner with the subjects being observed. For each stimulus observed, the observer marked the data collection sheet accordingly.

\section{Data Analysis}

Data are presented as the mean number of stimuli per hour and per category (i.e., received or emitted, causing or not causing an interruption). Manually collected data were entered into a database (MS Access, Microsoft, Seattle, Washington) and were analyzed using SPSS 15.0 (IBM, Armonk, New
York). The mean hourly number of stimuli was compared between 2010 and 2012 with the Student one-tailed $t$ test. Any $p$ value less than 0.05 was considered statistically significant.

Analysis for the secondary objective was based on the 4 stimuli targeted by the corrective measures: comings and goings, noise from printer/fax machines, face-to-face nonprofessional conversations, and Web browsing.

\section{RESULTS}

A total of 93 randomly scheduled 30-min observation periods were conducted: 62 between August 17 and September 2, 2010 (before the corrective measures) and 31 between June 19 and June 29, 2012 (after the corrective measures). A total of 2663 stimuli were observed in 2010 and 1217 in 2012.

For the main objective (evaluation of effectiveness of corrective measures), the overall mean hourly stimulus rate remained essentially unchanged: $85.9 \pm 22.2$ stimuli in 2010 and $78.5 \pm 20.1$ in 2012 ( $p=0.06$ ). Data are reported (by type of stimulus and by type of pharmacy professional) in Table 1.

For pharmacists, we observed a total of 1376 stimuli in 2010 and 598 in 2012. The mean hourly stimulus rate was $88.8 \pm 23.7$ in 2010 and $79.7 \pm 22.5$ in $2012(p=0.11)$. For pharmacy technicians, we observed a total of 1287 stimuli in 2010 and 619 in 2012. The mean hourly stimulus rate was $83.0 \pm 20.6$ in 2010 and $77.4 \pm 18.2$ in 2012 ( $p=0.18)$.

The mean hourly rate for stimuli received was $74.4 \pm 22.8$ per pharmacist in 2010 and $68.1 \pm 19.4$ in $2012(p=0.18)$. The corresponding mean hourly rate for stimuli received was $75.1 \pm 19.7$ per pharmacy technician in 2010 and $67.1 \pm 15.0$ in 2012 ( $p=0.08)$.

The mean hourly rate for stimuli causing interruptions (whether received or emitted) was $28.8 \pm 8.5$ stimuli per pharmacist in 2010 and $25.5 \pm 9.5$ in $2012(p=0.13)$. The corresponding mean hourly rate for stimuli causing interruptions (whether received or emitted) was $19.7 \pm 8.7$ per pharmacy technician in 2010 and $21.2 \pm 7.1$ in 2012 ( $p=0.28)$.

For the secondary objective (determining the effect of corrective measures), we compared hourly rates of stimuli related to the 4 corrective measures that were implemented in 2011 (Table 2). We observed statistically significant differences for all 4 targeted stimuli for pharmacists (i.e., comings and goings, noise from printer/fax machines, face-to-face nonprofessional conversations, and Web browsing) and for 2 of the targeted stimuli for pharmacy technicians (i.e., comings and goings, noise from printer/fax machines). These stimuli represented 18\% (688/3880) of all stimuli observed.

\section{DISCUSSION}

Few data have been published on the topic of interruptions in hospital pharmacies. This study reports measurements 
Table 1. Hourly Rate (Mean \pm Standard Deviation) of Stimuli Received and Emitted by Personnel in a Pharmacy Department Before and After Institution of Corrective Measures in 2011*

\begin{tabular}{|c|c|c|c|c|c|c|}
\hline \multirow[b]{2}{*}{ Type of Stimulus } & \multicolumn{2}{|c|}{ Pharmacists } & \multicolumn{4}{|c|}{ Pharmacy Technicians } \\
\hline & Before (2010) & After (2012) & $p$ value & Before (2010) & After (2012) & $p$ value \\
\hline \multicolumn{7}{|l|}{ Received } \\
\hline $\begin{array}{l}\text { Not a systematic cause } \\
\text { of interruptions }{ }^{\circ}\end{array}$ & $\begin{array}{c}55.8 \pm 19.9 \\
(63 \%)\end{array}$ & $\begin{array}{c}51.3 \pm 15.5 \\
(64 \%)\end{array}$ & 0.22 & $\begin{array}{c}61.4 \pm 20.7 \\
(74 \%)\end{array}$ & $\begin{array}{c}53.3 \pm 13.6 \\
(69 \%)\end{array}$ & 0.08 \\
\hline Systematic cause of interruptionsł & $\begin{array}{c}18.6 \pm 5.9 \\
(21 \%)\end{array}$ & $\begin{array}{c}16.8 \pm 8.3 \\
(21 \%)\end{array}$ & 0.20 & $\begin{array}{c}13.7 \pm 6.6 \\
(17 \%)\end{array}$ & $\begin{array}{c}13.8 \pm 5.8 \\
(18 \%)\end{array}$ & 0.48 \\
\hline \multicolumn{7}{|l|}{$\overline{\text { Emitted }}$} \\
\hline $\begin{array}{l}\text { Not a systematic cause of } \\
\text { interruptions } \S\end{array}$ & $\begin{array}{c}4.2 \pm 3.9 \\
(5 \%)\end{array}$ & $\begin{array}{c}2.9 \pm 4.1 \\
(4 \%)\end{array}$ & 0.16 & $\begin{array}{c}1.9 \pm 2.4 \\
(2 \%)\end{array}$ & $\begin{array}{c}2.9 \pm 2.9 \\
(4 \%)\end{array}$ & 0.11 \\
\hline Systematic cause of interruptions & $\begin{array}{c}10.2 \pm 6.3 \\
(11 \%)\end{array}$ & $\begin{array}{c}8.7 \pm 3.5 \\
(11 \%)\end{array}$ & 0.19 & $\begin{array}{c}6.0 \pm 4.7 \\
(7 \%)\end{array}$ & $\begin{array}{c}7.4 \pm 3.6 \\
(9 \%)\end{array}$ & 0.16 \\
\hline Total & $\begin{array}{c}88.8 \pm 23.7 \\
(100 \%)\end{array}$ & $\begin{array}{c}79.7 \pm 22.5 \\
(100 \%)\end{array}$ & 0.11 & $\begin{array}{c}83.0 \pm 20.6 \\
(100 \%)\end{array}$ & $\begin{array}{c}77.4 \pm 18.2 \\
(100 \%)\end{array}$ & 0.18 \\
\hline
\end{tabular}

*Percentages were calculated on the basis of overall mean number of stimuli received and emitted by each staff group in each phase of the study (before and after implementation of the corrective measures).

tGeneral calls through the main hospital speaker system, other people's conversations in the target area, noise from the printer/fax machines, noise from the pneumatic tube system, noise from hand-dryers, other people's phones ringing, other people answering the phone, comings and goings, fire alarms.

¥Web browsing (including social media sites such as Facebook), alerts from packing machines, technical problems, colleagues' questions, interactions with people at the reception wicket, information searches for prescription entry and validation, resolution of prescription entry issues, task changes, subject's phone ringing, provision of answers to colleagues, and miscellaneous stimuli, including head movements.

$\S$ Transferring phone calls, talking to oneself, face-to-face nonprofessional conversations.

IFace-to-face professional conversations and miscellaneous stimuli, including interactions with people that were not classified as face-to-face nonprofessional and professional conversations.

Table 2. Hourly Rate (Mean \pm Standard Deviation) of 4 Stimuli Related to Corrective Measures Implemented in 2011

\begin{tabular}{|c|c|c|c|c|c|c|}
\hline \multirow[b]{2}{*}{ Stimulus } & \multicolumn{2}{|c|}{ Pharmacists } & \multicolumn{4}{|c|}{ Pharmacy Technicians } \\
\hline & Before (2010) & After (2012) & $p$ value & Before (2010) & After (2012) & $p$ value \\
\hline Comings and goings & $5.7 \pm 4.3$ & $13.2 \pm 5.9$ & $<0.001$ & $5.4 \pm 3.9$ & $13.7 \pm 5.7$ & $<0.001$ \\
\hline $\begin{array}{l}\text { Face-to-face nonprofessional } \\
\text { conversations }\end{array}$ & $4.4 \pm 4.2$ & $1.2 \pm 1.8$ & 0.003 & $2.6 \pm 2.5$ & $1.7 \pm 1.6$ & 0.11 \\
\hline Printer/fax noise & $3.7 \pm 2.4$ & $0.6 \pm 1.8$ & $<0.001$ & $4.7 \pm 3.2$ & $0.8 \pm 1.8$ & $<0.001$ \\
\hline Web browsing & $1.3 \pm 2.2$ & $0 \pm 0$ & 0.009 & $0.6 \pm 1.3$ & $0.1 \pm 0.5$ & 0.07 \\
\hline
\end{tabular}

of stimuli observed in the dispensing area of a pharmacy department in an academic hospital centre in 2010 and 2012. Despite the implementation in 2011 of several measures aimed at reducing noise, stimuli, distractions, and interruptions, there was no reduction in the overall hourly rate of stimuli between the 2 data collection periods.

Mean hourly rates of stimuli observed in this study were higher than those reported in similar studies in other health care settings. ${ }^{1,8-13}$ In one study of pharmacy practice, pharmacists and pharmacy technicians were exposed to 6 interruptions per hour, while physicians and nurses were each exposed to 4 to 10 interruptions per hour. ${ }^{1}$

An analysis of 4 stimuli related to the corrective measures implemented in 2011 highlighted significant reductions in certain stimuli for certain groups of pharmacy professionals.
Between 2010 and 2012, nonprofessional conversations and Web browsing during work time declined for pharmacists but not for pharmacy technicians. The adoption of policies and procedures (e.g., limiting non-work-related Web browsing to breaks) may have a greater impact on pharmacists than on technicians. Replacing printer/fax machines with a digital prescription system undoubtedly reduced the noise caused by printing faxes that personnel received. Conversely, optimal reorganization of the dispensing area is still required, as this location remains a high-traffic area providing access to other areas within the department, a situation that is conducive to discussions of all sorts. The 4 targeted stimuli represented $18 \%$ of the overall number of stimuli observed during both observation phases. 
Although no statistically significant difference was observed in the hourly number of stimuli between 2010 and 2012, staff members had the general impression that the noise level was lower in 2012. An evaluation of the intensity of stimuli might have shown different results.

In performing this study, our objective was not to establish a link between interruptions and medication errors. Some authors, however, have suggested an associative link between interruptions and medication errors. Flynn and others ${ }^{1}$ filmed US pharmacy staff involved in dispensing over a 23-day period to evaluate the final accuracy checks of dispensed medication. Details of dispensing errors recorded by the observers were analyzed, taking into account ambient noise, distractions, and interruptions captured by videotaping. Both distractions and interruptions per half hour were significantly associated with dispensing errors ( $p=0.012$ and $p=0.004$, respectively). Beso and others ${ }^{5}$ reported that a 16 -member panel in a 450 -bed institution in the United Kingdom judged that distractions and interruptions were the cause of dispensing errors in 4\% (4/106) and $9 \%(10 / 106)$, respectively, of error-producing conditions.

This study had some limitations. First, this was an observational study, and it can be difficult to conduct such studies without staff member' knowledge. As such, study subjects in both phases may have been influenced by the presence of the observer. The study involved 62 observation periods in 2010 but only 31 in 2012. Although a single observer performed all observations in each phase (before and after implementation of corrective measures), the observer was a different person in each phase. The study did not take into consideration the particular staff members who were present during the observation periods, although it was known that some individuals emitted more stimuli than did others. The stimuli were measured and recorded by the observer, and these observations may have been different from the stimuli as perceived by the subjects who were being observed. The intensity of the stimuli was not evaluated. Future studies are required to assess a possible link between medication errors and stimuli, distractions, and interruptions.

\section{CONCLUSIONS}

Few data have been published on stimuli, distractions, and interruptions in hospital pharmacy practice. This descriptive study highlighted that more than 80 stimuli per hour were received or emitted by pharmacists and pharmacy technicians. Despite corrective measures taken in 2011, there was no statistically significant change in mean stimulus rate between 2010 and 2012. Other studies are needed to better characterize the nature of stimuli, distractions, and interruptions and their repercussions.

\section{References}

1. Flynn EA, Barker KN, Gibson JT, Pearson RE, Berger BA, Smith LA. Impact of interruptions and distractions on dispensing errors in an ambu- latory care pharmacy. Am J Health Syst Pharm. 1999;56(13):1319-25.

2. Charbotel B, Croidieu S, Vohito M, Guerin AC, Renaud L, Jaussaud J, et al. Working conditions in call-centers, the impact on employee health: a transversal study. Part II. Int Arch Occup Environ Health. 2009;82(6): 747-56.

3. Sohlberg MM, Mateer CA. Theory and remediation of attention disorders. In: Sohlberg MM, Mateer CA, editors. Introduction to cognitive rehabilitation: theory and practice. New York (NY): Guilford Press; 1989. p. 110-35.

4. Sinclair A, Slimm M, Terry D. To investigate how disruptive interruptions are on paediatric dispensary accuracy checkers [abstract]. Arch Dis Child. 2012;97(5):e17.

5. Beso A, Franklin BD, Barber N. The frequency and potential causes of dispensing errors in a hospital pharmacy. Pharm World Sci. 2005;27(3):182-90.

6. Santell JP, Cousins DD, Hicks R. USP drug safety review: Distractions contribute to medication errors. Drug Top Health Syst Ed. 2003 Nov 17 [cited 2012 Jun 29]:HSE42. Available from: www.usp.org/pdf/EN/ patientSafety/drugSafetyReview2003-11-17.pdf

7. Guérin A, Raimbault M, Lebel D, Bussières JF. Étude descriptive des interruptions dans un département de pharmacie [abstract]. Pharmactuel. 2012;45(2):81.

8. Chisholm CD, Dornfeld AM, Nelson DR, Cordell WH. Work interrupted: a comparison of workplace interruptions in emergency departments and primary care offices. Ann Emerg Med. 2001;38(2):146-51.

9. Coiera EW, Jayasuriya RA, Hardy J, Bannan A, Thorpe ME. Communication loads on clinical staff in the emergency department. Med J Aust. 2002;176(9):415-8.

10. Laxmisan A, Hakimzada F, Sayan OR, Green RA, Zhang J, Patel VL. The multitasking clinician: decision-making and cognitive demand during and after team handoffs in emergency care. Int J Med Inform. 2007;76 (11-12):801-11.

11. Biron AD, Loiselle CG, Lavoie-Tremblay M. Work interruptions and their contribution to medication administration errors: an evidence review. Worldviews Evid Based Nurs. 2009;6(2):70-86.

12. McGillis Hall L, Pedersen C, Fairley L. Losing the moment: understanding interruptions to nurses' work. J Nurs Adm. 2010;40(4):169-76.

13. Biron AD, Lavoie-Tremblay M, Loiselle CG. Characteristics of work interruptions during medication administration. J Nurs Scholarsh. 2009; 41(4):330-6.

Aurélie Guérin is a research assistant with the Pharmacy Practice Research Unit, Centre hospitalier universitaire Sainte-Justine, Montréal, Quebec, and a pharmacy intern at Université Paris Sud XI, Paris, France, where she is also a DPharm candidate.

Élaine Caron, BPharm, MSc, is a Pharmacist in the Department of Pharmacy and the Pharmacy Practice Research Unit, Centre hospitalier universitaire Sainte-Justine, Montréal, Quebec.

Denis Lebel, BPharm, MSc, FCSHP, is Assistant Director of the Department of Pharmacy and the Pharmacy Practice Research Unit, Centre hospitalier universitaire Sainte-Justine, Montréal, Quebec.

Jean-François Bussières, BPharm, MSC, FCSHP, is Director of the Department of Pharmacy and the Pharmacy Practice Research Unit, Centre hospitalier universitaire Sainte-Justine, and Professor, Faculty of Pharmacy, Université de Montréal, Montréal, Quebec.

\section{Competing interests: None declared.}

\section{Address correspondence to:}

Jean-François Bussières

Department of Pharmacy

Centre hospitalier universitaire Sainte-Justine

3175, chemin de la Côte Sainte-Catherine

Montréal QC H3T 1C5

e-mail: jf.bussieres@ssss.gouv.qc.ca 